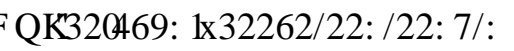

\title{
MODELLING OF SHIP'S DRAUGHT MEASUREMENT ERROR FOR SAFETY UNDERKEEL CLEARANCE DETERMINATION
}

\section{MODELOWANIE BLECDU ODCZYTU ZANURZENIA STATKU DO OKREŚLANIA BEZPIECZNEGO ZAPASU WODY POD STĘPKĄ}

\author{
Marta Schoeneich \\ Maritime University of Szczecin \\ Akademia Morska w Szczecinie \\ 70-500 Szczecin Wały Chrobrego 1-2 \\ martas@am.szczecin.pl
}

\begin{abstract}
In the article expert research result are presented concerning ship's draught measurement error. The questionnaire was carried out in the group of navigation experts and used for building the model of ship's draught determination error. The results are implied in model for safety underkeel clearance determination.
\end{abstract}

Keywords: expert research, ships draught, underkeel clearance

Streszczenie: W artykule przedstawiono wyniki badań ekspertowych, dotyczących błędu wizualnego odczytu zanurzenia statku. Ankieta została przeprowadzona w grupie ekspertów w dziedzinie nawigacji morskiej i wykorzystana do budowy modelu błędu określania zanurzenia. Uzyskane wyniki wykorzystano w modelu określania bezpiecznej rezerwy wody pod stępką statku.

Słowa kluczowe: badania ekspertowe, zanurzenie statku, zapas wody pod stępką 


\section{MODELLING OF SHIP'S DRAUGHT MEASUREMENT ERROR FOR SAFETY UNDERKEEL CLEARANCE DETERMINATION}

\section{Introduction}

Ship's draught is one of the basic elements which decide about navigation safety for restricted areas. Practical meaning of the ship's draught is actual maximum draught $\left(\mathrm{T}_{\max }\right)$. The draught including the ship's trim has an influence on the maneuver and speed characteristics [1].

Ship's draught is calculated on the basis weight changes before entering the port. These changes are caused by the fuel and reserves consumption, ballast operations, salinity changes and ship's heel deformation. Draught calculation is calculating with some accuracy value of ship's draught determination error [4]. Ship's draught determination error is one of the components which influence correct underkeel clearance determination. The basic navigator's responsibility is to keep safe underkeel clearance for ship's safety. Expert questionnaire was prepared in order to specify ship's draught determination error scale. The questionnaire was carried out among qualified members of crew responsible for correct ship's draught determination (Chief Officers and Master Mariners). The results were used for building model of ship's draught determination error in probabilistic model of ship's underkeel clearance.

\section{Questionnaire and research assumptions}

The knowledge of the group of navigation experts was used for building the model of ship's draught determination error. The expert method was chosen due to high costs of the experiment and access to experts in Szczecin Port. The questionnaire was characterized by concentrated construction, which made it possible to obtain detailed information concerning ship's draught measurement error. Questionnaire construction consisted of the following issues:

- estimation of ship's draught measurement error depending on the ship's draught marks availability, day time and wave height,

- estimation of ship's draught prediction error in port of destination depending on the ship's length and the duration of voyage, 
- accuracy of ship's draught measurement with draught marks using feet in comparison to metric scale.

Every expert chose the proper answer or wrote a different value on the questionnaire. It was also possible for the experts to give some additional information concerning the questionnaire.

\section{Research results}

Expert research was carried out in the group of 62 Chief Officers and Master Mariners. Some people abstained from answering for particular questions. The following results are showed.

\subsection{Ship's draught measurement error in various conditions}

Questionnaire results for ship's draught measurement error depending on the wave height are presented in Figure 1.

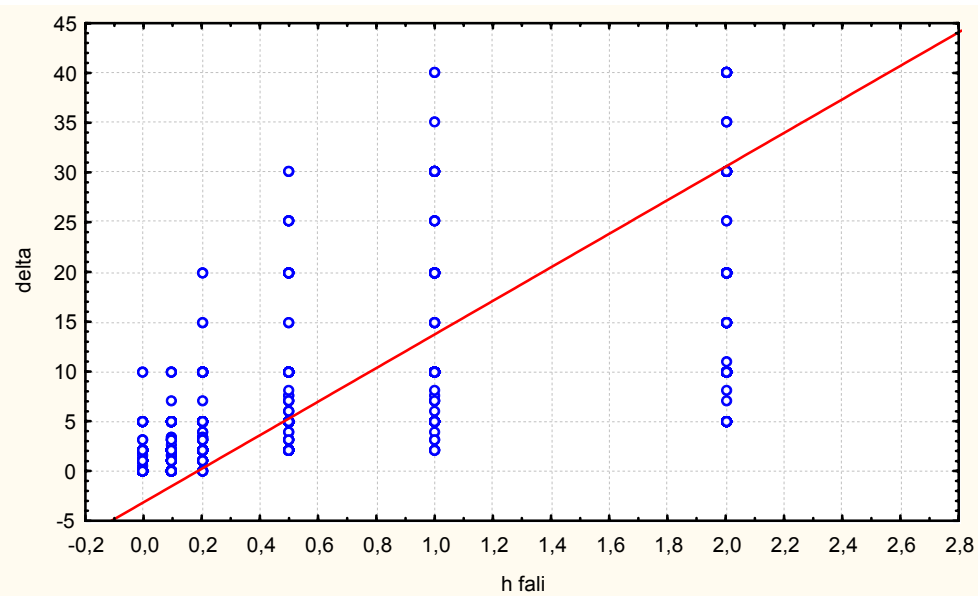

Fig. 1. Ship's draught measurement error [cm] depending on wave height $[\mathrm{m}]$.

Determination coefficient for linear regression is $\mathrm{R}^{2}=0,44$

The examples of histograms of ship's draught measurement error are presented in Figures 2 and 3. 


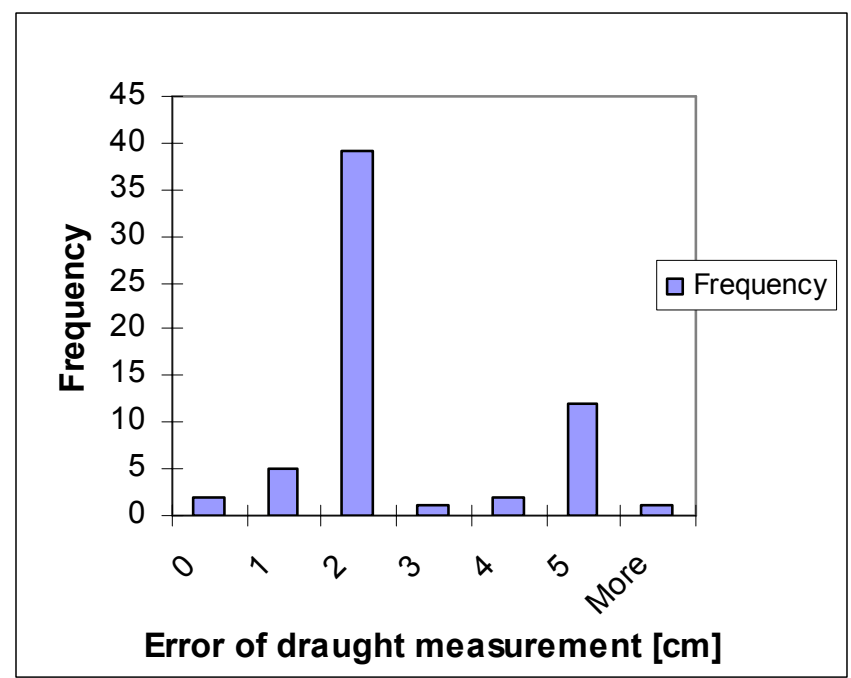

Fig. 2. Histogram of ship's draught measurement error during the day at wave height $0,2 \mathrm{~m}$. Good availability for draught marks.

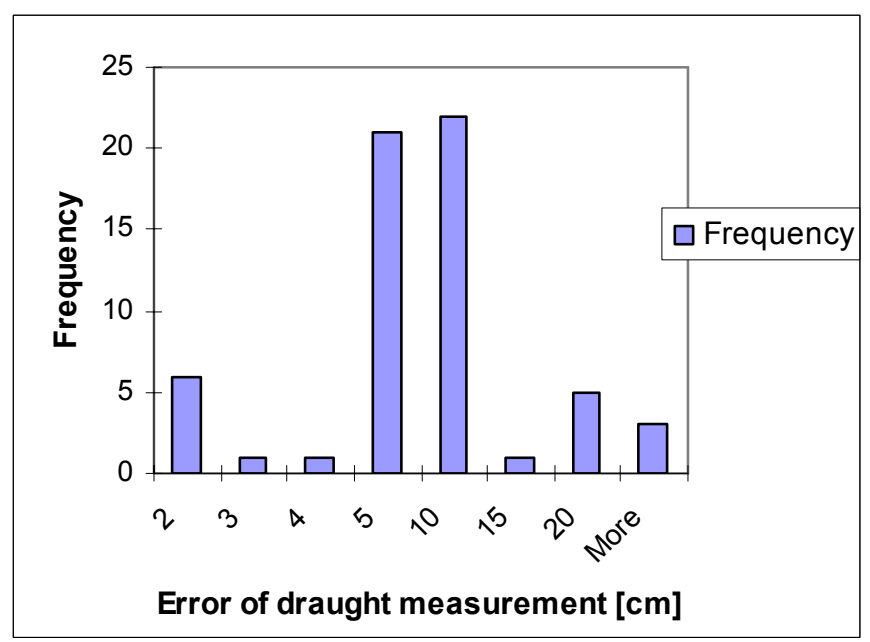

Fig. 3. Histogram of ship's draught measurement error during the night at wave height $0,5 \mathrm{~m}$. Problematic availability for draught marks.

Next, the null hypothesis was selected in order to conduct the one-way analysis of variance.

$\mathrm{H}_{0}: \mathrm{m}_{\mathrm{h}=0}=\mathrm{m}_{\mathrm{h}=0,1}=\mathrm{m}_{\mathrm{h}=0,2}=\mathrm{m}_{\mathrm{h}=0,5}=\mathrm{m}_{\mathrm{h}=1}=\mathrm{m}_{\mathrm{h}=2}$

versus alternative hypothesis:

$$
\mathrm{H}_{1}: \mathrm{m}_{\mathrm{h}=0} \neq \mathrm{m}_{\mathrm{h}=0,1} \neq \mathrm{m}_{\mathrm{h}=0,2} \neq \mathrm{m}_{\mathrm{h}=0,5} \neq \mathrm{m}_{\mathrm{h}=1} \neq \mathrm{m}_{\mathrm{h}=2}
$$


Taking into account the results depending on day time and availability for draught marks on the basis of probability results $p<\alpha$, where $\alpha=0,05$ in this case null hypothesis is rejected, therefore ship's draught measurement error depends on wave height. Similar analyses were conducted taking into account the influence of availability to draught marks and the day time. Either the ship's draught measurement during day time or good or problematic availability to draught marks do not have a significant influence on ship's draught measurement error.

\subsection{Ship's draught prediction error in port of destination}

In order to check if the time of voyage has an influence on the ship's draught measurement special analysis was conducted. The one-way analysis of variance for terror values was done for the following times of voyage:

1 - up to 5 days,

2- up to 10 days,

3- up to 20 days.

The null hypothesis was selected:

$$
\mathrm{H}_{0}: \mathrm{m}_{1}=\mathrm{m}_{2}=\mathrm{m}_{3}
$$

versus alternative hypothesis: $\mathrm{H}_{1}: \mathrm{m}_{1} \neq \mathrm{m}_{2} \neq \mathrm{m}_{3}$

The analysis conducting at the $\alpha=0,05$ level of significance showed that the null hypothesis should be rejected because there are no differences concerning values of ship's draught prediction terror depending on the ship's length. Critical level of probability has reached a low value thus draught measurement error in port of destination depends on ship's time of voyage.

Next, the assumption verifying ship's length influence on ship's draught prediction error in port of destination was made.

$\mathrm{H}_{0}$ : mean ship's draught forecast errors for ship with length $\mathrm{L}<100 \mathrm{~m}$ and ship with length $\mathrm{L}>100 \mathrm{~m}$ are not different, and

$\mathrm{H}_{1}$ : mean ship's draught forecast errors for ship with length $\mathrm{L}<100 \mathrm{~m}$ and ship with length $\mathrm{L}>100 \mathrm{~m}$ are fundamentally different.

T-test was used for hypotheses verification. Critical level of probability $p=0,31$ at the significance level $\alpha=0,05$, which does not give any reasons to reject null hypothesis describing equal means of ship's draught prediction error in port of destination for ship's with length less than $100 \mathrm{~m}$ and longer than $100 \mathrm{~m}$.

Since the equal variance was made In the above test the following assumptions was also verified using $\mathrm{H}_{0}: \sigma_{1}^{2}=\sigma_{2}^{2}$ 
versus alternative hypothesis: $\mathrm{H}_{1}: \sigma_{1}^{2} \neq \sigma_{2}^{2}$

Null hypothesis was verified using $F$ - Snedecora test. Critical level of probability $\mathrm{p}=0,063$ was obtained therefore the assumptions of equal variances can be taken into account. As a result the ship's length do not have a significant influence on ship's draught prediction error in port of destination.

\subsection{Error of draught measurement depending on draught scale}

According to the experts, who took part in the questionnaire, error of ship's draught measurement in feet shows unimportant values of error from 0 to $5 \mathrm{~cm}$. Error of draught measurement in feet in comparison to metric scale is $\mathrm{m}_{\delta}=1,31[\mathrm{~cm}]$. Frequency of error values is presented in Figure 4.

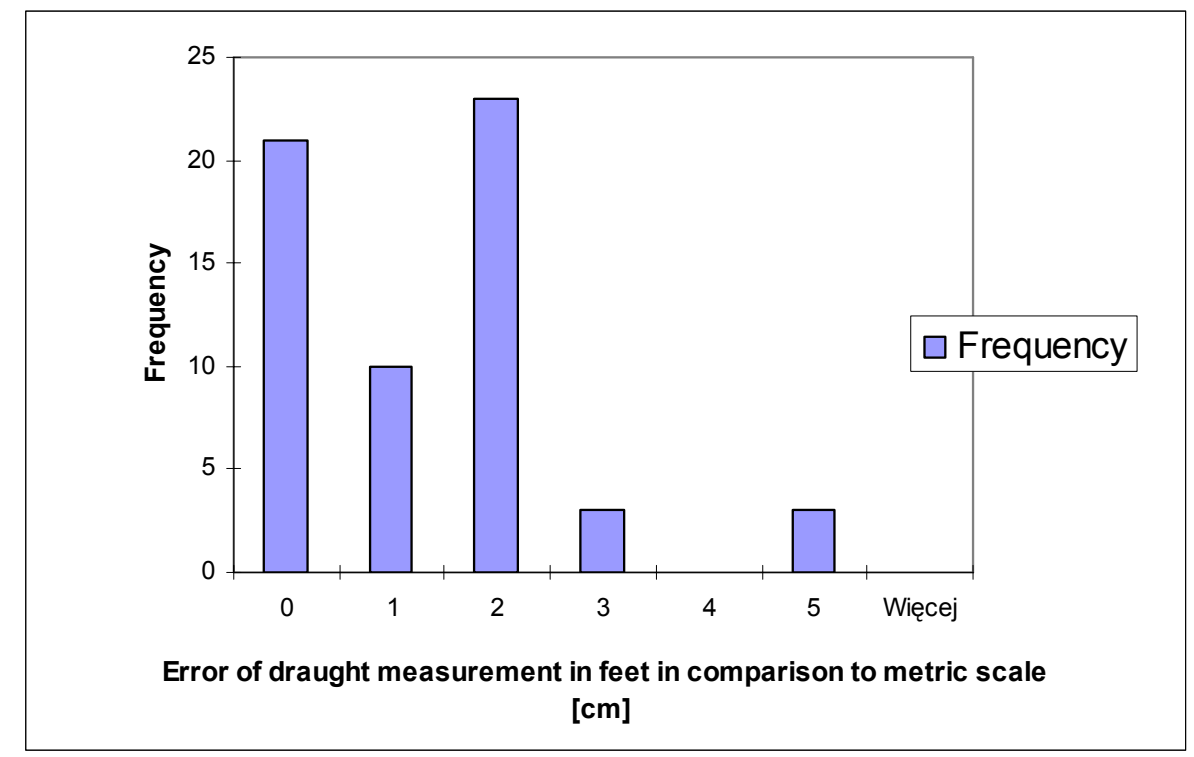

Fig. 4. Histogram of ship's draught measurement error in feet in comparison to metric scale.

\subsection{Model of ship's draught measurement error}

The results of the expert questionnaire were helpful to create the following multiple regression model.

The following model of ship's draught measurement error was obtained

$$
\delta_{T}=-2,31+8,51 h_{f}+1,13 w_{1}+1,67 w_{2}[\mathrm{~cm}]
$$


, where:

$$
\begin{array}{ll}
h_{f} \quad-\quad \text { wave height }[\mathrm{m}] \\
w_{1}-\quad \text { day }\left(w_{1}=1\right) \text { or night }\left(w_{1}=2\right) \text { time coefficient } \\
w_{2}-\quad \begin{array}{l}
\text { draught marks availability coefficient } \\
\left(w_{2}=1 \text { for good and } w_{2}=2\right. \text { for problematic draught marks } \\
\text { availability })
\end{array}
\end{array}
$$

Determination coefficient $\mathrm{R}^{2}$ of the suggested model is 0,45 and the standard error of estimation equals $6,34[\mathrm{~cm}]$.

Ship's draught measurement error allows to determine the probability of ships hull hitting the bottom, therefore the results will be used in probabilistic model of ship's underkeel clearance [2].

\section{Conclusions}

In the above article expert research results were presented. The main aim was to build model of ship's draught measurement error. It was stated that the error major factors are voyage duration and the wave height at the time of measurement, while ship's length impact is not that significant. of the has an influence on the ship's draught prediction in port of destination. As far as, the length of the ship is concerned, it turned out that it does not influence the ship's draught prediction error significantly. Ship's draught measurement error model will be implemented in the probabilistic model of ship's underkeel clearance. It will enable underkeel clearance modeling more accurate which in turn might bring increased profits without compromising safety on the restricted waters.

\section{References}

1. Gucma S., Jagniszczak I., Nawigacja morska dla kapitanów. Szczecin 2006.

2. Gucma L., Schoeneich M., Probabilistic Model of Underkeel Clearance in Decision Making Process of Port Captain. Monograph- Advances in Marine Navigation and Safety of Sea Transportation TransNav'2007, Gdynia 2007.

3. Jóźwiak J., Podgórski J., Statystyka od podstaw, Polskie Wydawnictwo Ekonomiczne, Warszawa 2006.

4. Jurdziński M., Nawigacyjne planowanie podróży. Wydawnictwo Morskie, Gdańsk 1989.

5. Stanisz A. Przystępny kurs statystyki, StatSoft Polska, Kraków 2007. 


\section{MODELOWANIE BLĘDU ODCZYTU ZANURZENIA STATKU DO OKREŚLANIA BEZPIECZNEGO ZAPASU WODY POD STĘPKA}

\section{Wstęp}

Zanurzenie statku jest jednym z podstawowych elementów decydujących o bezpieczeństwie nawigacji na akwenach ograniczonych. W praktyce pod pojęciem zanurzenia statku zazwyczaj rozumiane jest jego aktualne zanurzenie maksymalne $\left(\mathrm{T}_{\max }\right)$. Zanurzenie to łącznie $\mathrm{z}$ trymem statku ma decydujący wpływ na właściwości manewrowe i prędkościowe statku [1].

Przed wejściem do portu zanurzenie statku kalkulowane jest na podstawie zmian ciężaru spowodowanych zużyciem paliwa i zapasów, przeprowadzanych operacji balastowych, zmiany zasolenia oraz odkształceń kadłuba. Kalkulacja zanurzenia przeprowadzana jest z pewną dokładnością, z którą ściśle związana jest wartość rezerwy na błąd określenia zanurzenia statku[4]. Rezerwa na błąd określenia zanurzenia statku jest jednym $\mathrm{z}$ czynników wpływających na prawidłowe oszacowanie zapasu wody pod stępką. Utrzymanie niezerowego zapasu wody pod stępką jest $\mathrm{z}$ kolei podstawowym zadaniem nawigatora $\mathrm{w}$ zakresie zachowania bezpieczeństwa statku. W celu sprecyzowania wielkości błędu odczytu zanurzenia statku przygotowano ankietę ekspertową. Ankieta ta została przeprowadzona wśród wykwalifikowanych członków załogi statków odpowiedzialnych za prawidłowe określenie zanurzenia statku tj. starszych oficerów i kapitanów. Uzyskane wyniki wykorzystano do budowy modelu określania błędu zanurzenia statku w probabilistycznym modelu określania zapasu wody pod stępka.

\section{Opracowanie ankiety i założenia badań}

Dla potrzeb budowy modelu określania błędu zanurzenia statku wykorzystano wiedzę ekspertów $\mathrm{z}$ dziedziny nawigacji morskiej. Zdecydowano się na metodę ekspertową ze względu na duże koszty przeprowadzenia eksperymentu rzeczywistego oraz bezpośredni dostęp do ekspertów w porcie Szczecin. Przygotowana ankieta charakteryzowała się zwartą konstrukcją, umożliwiająca uzyskanie szczegółowych danych, 
dotyczących błędu odczytu wizualnego statku przez nawigatora. Konstrukcja ankiety obejmowała następujące zagadnienia:

- ocenę błędu odczytu zanurzenia w zależności od dostępności do znaków zanurzenia, pory dnia lub nocy oraz falowania,

- ocenę błędu przewidywania zmiany zanurzenia w porcie docelowym w zależności od długości statku oraz długości podróży,

- dokładność odczytu zanurzenia statku z wykorzystaniem znaków zanurzenia $\mathrm{w}$ stopach $\mathrm{w}$ stosunku do skali metrycznej.

Ekspert zaznaczał właściwą odpowiedź bądź wpisywał inną wartość. Możliwe było również zamieszczenie dodatkowych uwag dotyczących tematyki ankiety.

\section{Wyniki badań}

Badania ekspertowe przeprowadzono w grupie 62 starszych oficerów lub kapitanów statku. Niektóre osoby wstrzymały się od odpowiedzi na poszczególne pytania. Uzyskano następujące wyniki.

\subsection{Btąd odczytu zanurzenia statku w różnych warunkach}

Wyniki ankiety dotyczące błędu odczytu zanurzenia w zależności od wysokości fali przedstawiono na rysunku 1.

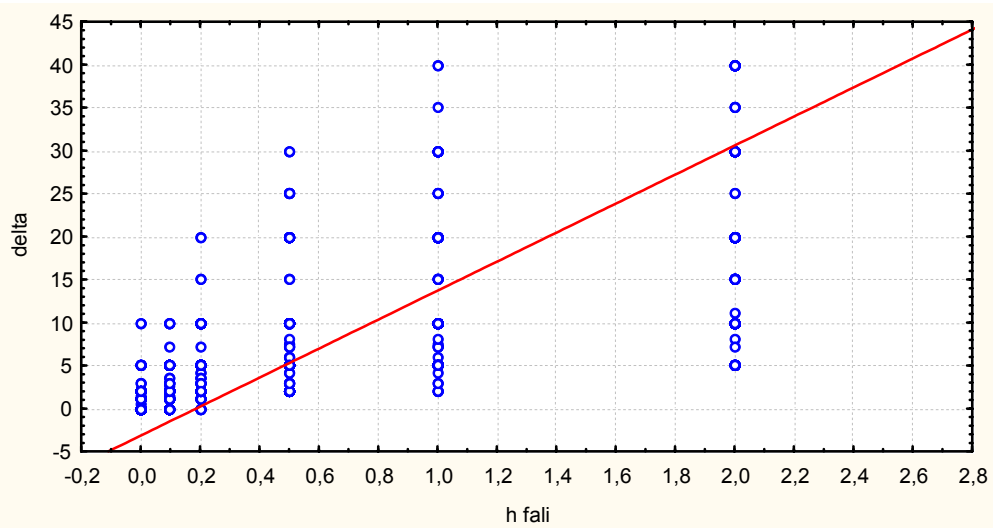

Rys. 1. Błąd odczytu zanurzenia statku [cm] w zależności od wysokości fali[m].

Współczynnik determinacji dla otrzymanej regresji liniowej wynosi $\mathrm{R}^{2}=0,44$

Przykładowe histogramy błędów odczytu wizualnego zanurzenia przedstawione są na rysunkach 2 i 3 . 


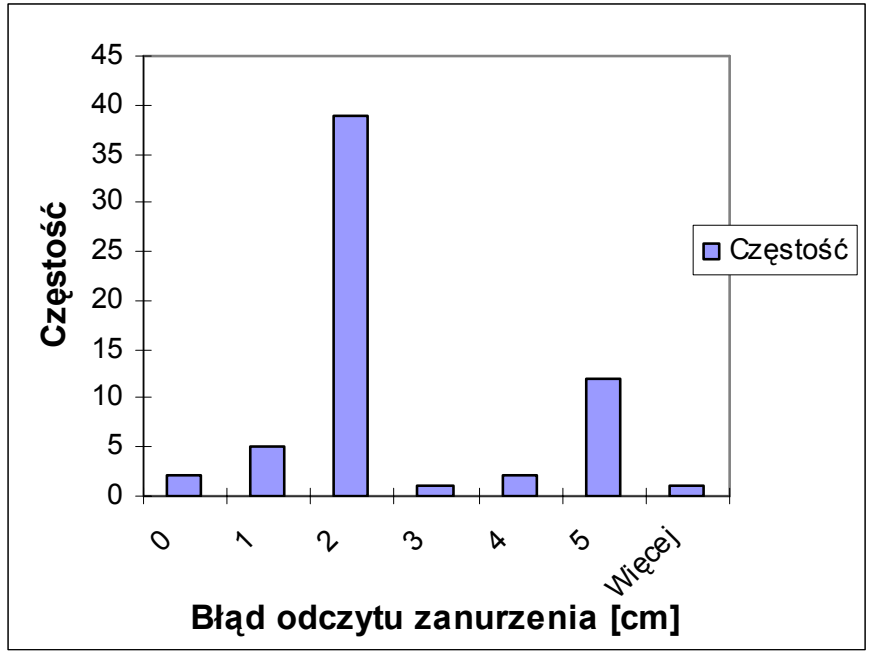

Rys.2. Histogram błędu odczytu zanurzenia w dzień przy falowaniu 0,2m.

Dobra dostępność do znaków zanurzenia.

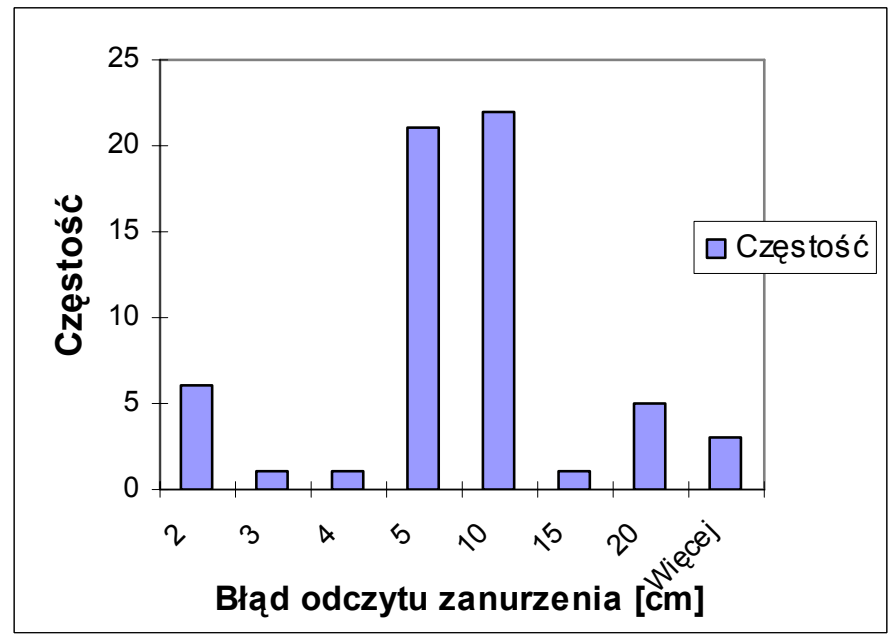

Rys. 3. Histogram błędu odczytu zanurzenia w dzień przy falowaniu 0,5m. Utrudniona dostępność do znaków zanurzenia.

Następnie w celu przeprowadzenia analizy wariancji $\mathrm{z}$ klasyfikacją pojedynczą wyznaczono hipotezę zerową

$$
\mathrm{H}_{0}: \mathrm{m}_{\mathrm{h}=0}=\mathrm{m}_{\mathrm{h}=0,1}=\mathrm{m}_{\mathrm{h}=0,2}=\mathrm{m}_{\mathrm{h}=0,5}=\mathrm{m}_{\mathrm{h}=1}=\mathrm{m}_{\mathrm{h}=2}
$$
wobec hipotezy alternatywnej:

$$
\mathrm{H}_{1}: \mathrm{m}_{\mathrm{h}=0} \neq \mathrm{m}_{\mathrm{h}=0,1} \neq \mathrm{m}_{\mathrm{h}=0,2} \neq \mathrm{m}_{\mathrm{h}=0,5} \neq \mathrm{m}_{\mathrm{h}=1} \neq \mathrm{m}_{\mathrm{h}=2}
$$


Uwzględniając wyniki $\mathrm{w}$ zależności od pory dnia oraz dostępności do znaków zanurzenia na podstawie wyników prawdopodobieństwa $\mathrm{p}<\alpha$, gdzie $\alpha=0,05$ stwierdzono ,że należy odrzucić hipotezę zerową, a zatem błąd odczytu zanurzenia statku zależy od wysokości fali. Podobne analizy przeprowadzono również pod kątem wpływu dostępności do znaków zanurzenia oraz pory dnia lub nocy. Stwierdzono, że fakt dokonywania odczytu zanurzenia w dzień lub w nocy, podobnie jak dobra bądź utrudniona dostępność do znaków zanurzenia, nie mają znaczącego wpływu na błąd odczytu zanurzenia statku.

\subsection{Btad przewidywania zanurzenia w porcie docelowym}

W celu sprawdzenia czy długość podróży ma wpływ na błąd przewidywania zanurzenia $\mathrm{w}$ porcie docelowym, przeprowadzono analizę wariancji dla wartości błędów określonych przez ekspertów dla podróży trwającej:

$$
\begin{aligned}
& \text { 4- do } 5 \text { dni, } \\
& 5-\text { do } 10 \text { dni, } \\
& \text { 6- do } 20 \text { dni. }
\end{aligned}
$$

Została postawiona hipoteza zerowa

$$
\mathrm{H}_{0}: \mathrm{m}_{1}=\mathrm{m}_{2}=\mathrm{m}_{3}
$$

wobec hipotezy alternatywnej: $\mathrm{H}_{1}: \mathrm{m}_{1} \neq \mathrm{m}_{2} \neq \mathrm{m}_{3}$

Przeprowadzona analiza na poziomie istotności $\alpha=0,05$ wykazała, iż należy odrzucić hipotezę zerową o tym, że nie występują różnice w wartościach błędu przewidywania zanurzenia statku w porcie docelowym w zależności od długości podróży statku. Wartość krytyczna prawdopodobieństwa osiągnęła niewielką wartość, a zatem błąd przewidywania zanurzenia statku w porcie docelowym zależy od okresu podróży danego statku.

Następnie postawiono hipotezy, weryfikujące wpływ długości statku na błąd przewidywania zanurzenia statku w porcie docelowym.

$\mathrm{H}_{0}$ : średnie błędy przewidywania zanurzenia statku o długości $\mathrm{L}<100 \mathrm{~m} \mathrm{i}$

statku o długości L $>100 \mathrm{~m}$ nie różnią się, oraz

$\mathrm{H}_{1}$ : średnie błędy przewidywania zanurzenia statku o długości $\mathrm{L}<100 \mathrm{~m}$ i statku o długości L $>100 \mathrm{~m}$ są istotnie różnie.

Do zweryfikowania hipotez wykorzystano test $t$-Studenta o równości średnich. Obliczona wartość krytyczna prawdopodobieństwa wyniosła $\mathrm{p}=0,31$ na poziomie istotności $\alpha=0,05$, co nie daje podstaw do odrzucenia hipotezy zerowej, mówiącej o równości średnich błędów przewidywania zanurzenia statku w porcie docelowym dla statków o długości mniejszej od $100 \mathrm{~m}$ i większych. 
Ponieważ w powyższym teście założono równość wariancji, zweryfikowano również to założenie wyznaczając hipotezę $\mathrm{H}_{0}: \sigma_{1}^{2}=\sigma_{2}^{2}$

przeciwko hipotezie alternatywnej: $\mathrm{H}_{1}: \sigma_{1}^{2} \neq \sigma_{2}^{2}$

Hipotezę zerową zweryfikowano wykorzystując test $F$ - Snedecora. Otrzymano prawdopodobieństwo prawdziwości hipotezy zerowej $\mathrm{p}=0,063$, zatem założenie o równości wariancji może być utrzymane, a więc długość statku nie wpływa na wartość błędu przewidywania zanurzenia w porcie przeznaczenia.

\subsection{Btąd odczytu zanurzenia $w$ zależności od wykorzystywanej skali zanurzenia}

Według ankietowanych odczyt zanurzenia statku w stopach charakteryzuje się niewielkim błędem o wartościach od 0 do $5 \mathrm{~cm}$. Średni błąd odczytu zanurzenia $\mathrm{w}$ stopach $\mathrm{w}$ stosunku do skali metrycznej wynosi $\mathrm{m}_{\delta}=1,31$ [cm]. Częstość wartości błędów zaprezentowano na rysunku nr 4.

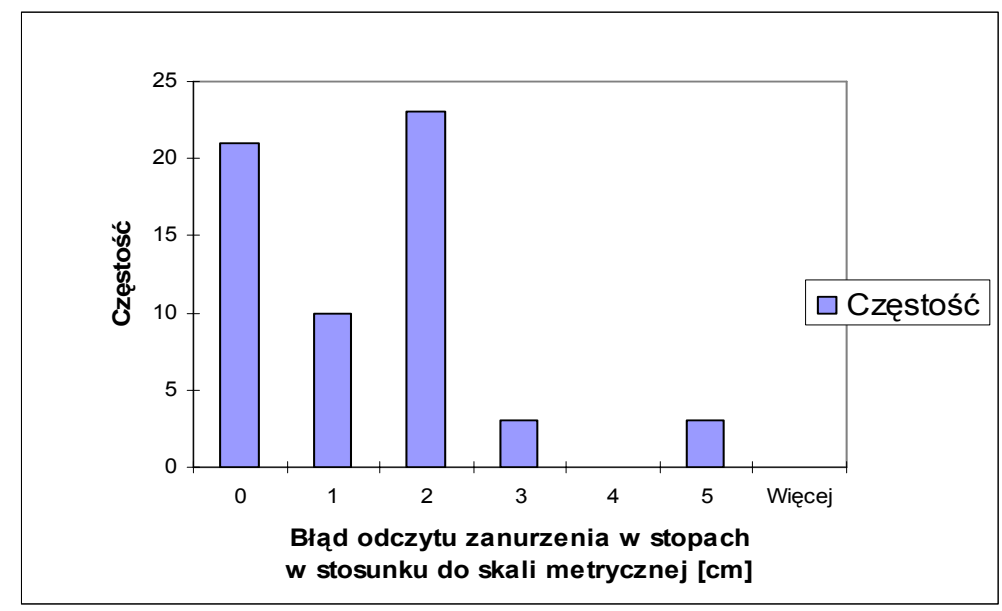

Rys. 4. Histogram błędu odczytu zanurzenia statku w stopach w stosunku do skali metrycznej.

\subsection{Model btędu odczytu zanurzenia statku}

Wyniki przeprowadzonej ankiety ekspertowej posłużyły do stworzenia następującego modelu regresji z wieloma zmiennymi niezależnymi.

Uzyskano następujący model błędu odczytu wizualnego statku

$$
\delta_{T}=-2,31+8,51 h_{f}+1,13 w_{1}+1,67 w_{2}[\mathrm{~cm}]
$$


gdzie:

$$
\begin{array}{lll}
h_{f} & - & \text { wysokość fali }[\mathrm{m}] \\
w_{1} & - & \text { współczynnik dotyczący pory dnia } w_{1}=1 \text { lub nocy } w_{1}=2 \\
w_{2} & -\quad & \text { współczynnik dostępności do znaków zanurzenia } \\
& \left(w_{2}=1 \text { dla dobrego oraz } w_{2}=2\right. \text { dla utrudnionego dostępu } \\
& \text { do znaków zanurzenia) }
\end{array}
$$

Współczynnik determinacji $\mathrm{R}^{2}$ proponowanego modelu wynosi 0,45 natomiast standardowy błąd estymacji jest równy $6,34[\mathrm{~cm}]$.

Uzyskane wyniki posłużyły do budowy modelu błędu odczytu zanurzenia statku. Błąd określenia zanurzenia statku jest jednym z czynników wpływających na określenie prawdopodobieństwa kolizji statku z dnem akwenu, dlatego otrzymane wyniki zostaną wykorzystane w probabilistycznym modelu określania bezpiecznego zapasu wody pod stępką statku [2].

\section{Podsumowanie}

W referacie przedstawiono wyniki badań ekspertowych, przeprowadzonych celem budowy modelu błędu wizualnego odczytu zanurzenia statku przez nawigatora. Stwierdzono, że długość podróży ma wpływ błąd przewidywania zanurzenia statku w porcie docelowym natomiast długość statku nie wpływa znacząco na tę wartość. Określono, iż błąd odczytu zanurzenia statku zależy od wysokości fali. Model błędu wizualnego odczytu zanurzenia statku zostanie zaimplementowany do modelu probabilistycznego określania bezpiecznego zapasu wody pod stępką statku. Posłuży to do dokładniejszego określenia rezerwy wody pod stępką, co może wpłynąć na zwiększenie potencjalnych zysków przy zapewnieniu odpowiedniego poziomu bezpieczeństwa żeglugi na akwenach ograniczonych.

\section{Spis literatury}

1. Gucma S., Jagniszczak I., Nawigacja morska dla kapitanów. Szczecin 2006.

2. Gucma L., Schoeneich M., „Probabilistic Model of Underkeel Clearance in Decision Making Process of Port Captain." MonographAdvances in Marine Navigation and Safety of Sea Transportation TransNav'2007, Gdynia 2007. 
3. Jóźwiak J., Podgórski J., Statystyka od podstaw, Polskie Wydawnictwo Ekonomiczne, Warszawa 2006.

4. Jurdziński M., Nawigacyjne planowanie podróży. Wydawnictwo Morskie, Gdańsk 1989.

5. Stanisz A. Przystepny kurs statystyki, StatSoft Polska, Kraków 2007.

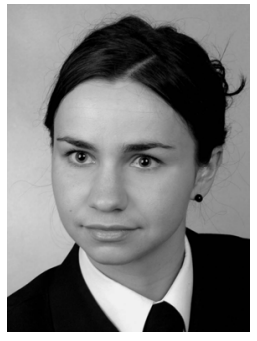

MSc. Eng. Marta SCHOENEICH, Maritime University of Szczecin, Poland. Member of Maritime Traffic Engineering research team. specialization: Marine Traffic Engineering, ship's underkeel clearance research. Several publications in field. 